\title{
Potential Effects of the New Medicare Prospective Payment System on Drug Prescription in End-Stage Renal Disease Care
}

\author{
Wolfgang C. Winkelmayer \\ Division of Nephrology, Stanford University School of Medicine, Palo Alto, Calif., USA
}

\section{Key Words}

End-stage renal disease $\cdot$ Patient care cost $\cdot$ Cost

reimbursement - Drug prescription - Patient outcomes .

Erythropoiesis-stimulating agents

\begin{abstract}
The Centers for Medicaid and Medicare Services have announced a new Prospective Payment System to reimburse the care furnished by dialysis centers to patients with endstage renal disease (ESRD). As of January 2011, most aspects of the outpatient treatment of patients with ESRD will be included in a single payment. In addition to the items previously included in the Composite Rate, injectable drugs and their oral equivalents will be included in this new capitation payment, as will the laboratory tests required for monitoring maintenance dialysis. As of January 2014 , oral-only medications will also be included. Physician payments and payments for inpatient care, as well as for care not directly related to ESRD care will continue to be reimbursed separately. Patterns of medication treatment of ESRD patients will likely be revisited, and one can expect pronounced adjustments. Treatment of anemia will likely shift towards less use of erythropoiesis-stimulating agents and somewhat towards higher use of intravenous iron supplements. Average hemoglobin concentrations will decline. Use of intravenous vitamin D analogues will likely be reduced and substituted with their oral equivalents in many patients. One can also expect
\end{abstract}

a temporary trend towards higher use of calcimetics, since their inclusion in the payment bundle is deferred until 2014. Treatment of problems with vascular access patency and of access infections will likely shift to the inpatient setting, and there may be reluctance to quickly accept recovering patients back to the outpatient setting after vascular access intervention. On aggregate, these changes have the potential to alter patient outcomes, but it is currently unclear how these will be and can be monitored.

Copyright $\odot 2011$ S. Karger AG, Basel

\section{Reimbursement of End-Stage Renal Disease in the US}

Almost 40 years ago (1972), the United States Congress mandated that patients with end-stage renal disease (ESRD) be covered for health insurance through the federal Medicare program. While Medicare is the primary health insurance program for older Americans (over age 65 years) and patients with certain disabilities, the coverage of patients with ESRD was and has remained unique in that patients can qualify for coverage as a result of their disease, regardless of their age. As a result, the Centers for Medicare and Medicaid Services (CMS, formally Health Care Financing Administration) pay for ESRD-related services and other health care for more than $90 \%$ of ESRD patients in the US. While it was originally assumed that only few patients would be eligible for such coverage and

\section{KARGER}

Fax +4161306 1234 E-Mail karger@karger.ch www.karger.com
(C) 2011 S. Karger AG, Basel

0253-5068/11/0313-0066\$38.00/0

Accessible online at:

www.karger.com/bpu
Wolfgang C. Winkelmayer, $\mathrm{MD}, \mathrm{ScD}$

Division of Nephrology, Stanford University School of Medicine

780 Welch Road, Suite 106

Palo Alto, CA 94304 (USA)

Tel. +1 650723 2387, Fax +1 650721 1443, E-Mail wcwl@ @stanford.edu 
that those would predominantly include younger (male) adults who could then maintain or regain a productive life in the workforce, the number of Medicare beneficiaries with ESRD has skyrocketed. In 2010, more than 570,000 Americans have ESRD and their health care cost CMS 24 billion, roughly $6 \%$ of the total Medicare budget (2007 data) [1].

Originally, the provision of ESRD care required plant and durable equipment (building, infrastructure, water purification systems, dialysis machines, chairs, etc.), overhead (e.g. clerical support, billing, etc.), disposable materials (tubing, dialysis filters, needles, dialysate concentrates, etc.), and nursing, technician, and auxiliary personnel time. Responding to the Omnibus Budget Reconciliation Act of 1981, payment for these items was bundled into a Composite Rate payment as of 1983. Inflationary adjustments to the Composite Rate have lagged behind the inflation for medical services, which has far exceeded the general inflation rate. Physician visits were billed separately and the specific payment schedule has changed somewhat over time. Laboratory testing was also billed separately. Prior to the introduction of erythropoiesis-stimulating agents (ESAs) for the treatment of anemia in ESRD patients, Medicare expenditures for intravenous medications in dialysis units were negligible. Starting in 1989, rapid adoption of epoetin alfa led to a significant increase in ESRD-related expenditures. Within a year of approval by the Food and Drug Administration of the first ESA, epoetin alfa, more than half of ESRD patients received this drug, and the costs exceeded 250 million USD in 1991 [1, 2]. With the availability and increasing adoption of intravenous vitamin $\mathrm{D}$ preparations as well as intravenous iron preparations, the overall expenditures for intravenous drugs soared and exceeded 2.7 billion USD in 2007; ESAs (epoetin alfa and darbepoetin alfa) accounted for more than three quarters of these expenditures [1]. Most recently, with the creation of an oral prescription drug benefit through Medicare Part D in 2006, Medicare is also responsible for the cost of noninjectable medications, including those that are specific for the care of ESRD patients. While such oral medications used to be few and relatively inexpensive, e.g. calcium-carbonate for phosphate binding or generic calcitriol, the advent of new, patent-protected medications such as sevelamer, lanthanum, cinacalcet, or oral vitamin D analogues, the cost for oral ESRD-related medications has also soared, totaling more than USD 450 million in 2007 [3].

In order to rein in the skyrocketing costs of the ESRD program, congress mandated payment reform in the
Medicare Modernization Act of 2003 and later in the Medicare Improvements for Patients and Providers Act of 2008, a prospective payment system that would expand the current Composite Rate to additionally include injectable medications and laboratory testing. After releasing a Proposed Rule in September 2009 with a subsequent comment period, CMS issued the Final Rule on the EndStage Renal Disease Prospective Payment System (PPS) on July 27, 2010 [3]. This new reimbursement system includes provisions that have the potential to fundamentally change utilization patterns of ESRD medications in the US.

\section{Provisions on Medications in the PPS}

The Final Rule mandates that all ESRD-specific injectable medications be covered as part of the future capitation system as of 1.1.2011. Five specific therapeutic areas were outlined (table 1). Of note, all oral equivalents of these drugs were also considered part of the PPS, even equivalent medications not yet on the market such as, e.g., oral ESAs. The likely consequences of these mandates on utilization of these covered drugs are listed in table 1 . In addition, oral-only ESRD drugs will also be included in the bundle, but not until 1.1.2014. Originally planned for immediate inclusion, CMS felt that including oral-only drugs as of 1.1.2011 posed several problems: providers may have difficulty setting up agreements with pharmacies or drug manufacturers by such short notice, especially smaller chains and independent units, who also might be disadvantaged on price. The Agency was also concerned about the appropriate pricing of the oralonly component into the bundle, since relatively fewer years of data since the launch of the Medicare Part D program in 2006 were available to study utilization and costs of the medications to be included.

\section{Anemia Care}

The highest impact of the bundle will be on anemia care. Previously incentivized to maximize use of ESAs, and to a certain extent, intravenous iron supplements, providers will now attempt to minimize the costs of anemia care. Most certainly, use of ESAs will decline quite drastically, especially in ESA hyporesponsive patients, who previously received excessive doses with little marginal benefit. Use of intravenous iron preparations is likely to increase, but its extent is difficult to predict. Current 
Table 1. Medications included in the PPS as of January 2011

\begin{tabular}{|c|c|c|c|}
\hline Drug category & $\begin{array}{l}\text { Drugs included } \\
\text { (oral equivalents also included) }\end{array}$ & Rationale for inclusion & Possible effect on practice \\
\hline Access management & Alteplase & $\begin{array}{l}\text { Drugs used to ensure access by removing clots } \\
\text { from grafts, reverse anticoagulation if too much } \\
\text { medication is given, and provide anesthetic for } \\
\text { access placement }\end{array}$ & $\begin{array}{l}\text { Creates incentive to admit patients for } \\
\text { treatment of access thrombosis }\end{array}$ \\
\hline Anemia management & $\begin{array}{l}\text { Epoetin alfa, darbepoetin alfa, } \\
\text { iron sucrose, sodium ferric } \\
\text { gluconate, iron dextrose }\end{array}$ & $\begin{array}{l}\text { Drugs used to stimulate red blood cell } \\
\text { production and treat and/or prevent anemia; } \\
\text { this category includes ESAs as well as iron }\end{array}$ & $\begin{array}{l}\text { Reduce doses of ESAs, especially for } \\
\text { hyporesponsive patients; } \\
\text { increase use of iron supplementation }\end{array}$ \\
\hline Anti-infectives & Daptomycin, vancomycin & $\begin{array}{l}\text { Daptomycin and vancomycin used to treat } \\
\text { access infections }\end{array}$ & $\begin{array}{l}\text { Creates incentive to admit patients for } \\
\text { treatment of access infections }\end{array}$ \\
\hline $\begin{array}{l}\text { Bone and mineral } \\
\text { metabolism }\end{array}$ & $\begin{array}{l}\text { Calcitriol, doxercalciferol, } \\
\text { paricalcitol }\end{array}$ & $\begin{array}{l}\text { Drugs to prevent/treat bone disease secondary } \\
\text { to dialysis }\end{array}$ & $\begin{array}{l}\text { Switch from intravenous to oral; switch } \\
\text { to calcitriol; increased use of cinacalcet }\end{array}$ \\
\hline Cellular management & Levocarnitine & $\begin{array}{l}\text { Drugs used for deficiencies of naturally } \\
\text { occurring substances needed for cellular } \\
\text { management }\end{array}$ & $\begin{array}{l}\text { Already minimal use, may further } \\
\text { decline }\end{array}$ \\
\hline
\end{tabular}

iron utilization patterns, ever increasing to include patients with higher ferritin concentrations, were rooted in a system that maximized ESA use. What can be predicted, however, is that providers will also attempt to maximize efficiency of iron supplementation, e.g. by using less expensive products. Thus, it is likely that we will see a resurgence of iron dextran use. The lack of quality evidence on the comparative safety among iron supplements will help justify such practice changes [4]. And finally, practice will shift towards maintenance iron supplementation regimens using regular low doses, from approaches employing short courses of higher dose repletion followed by periods of no repletion, especially if currently ongoing research demonstrates the superiority of maintenance dosing.

\section{Bone and Mineral Metabolism}

Most ESRD patients in the US receive intravenous treatment with vitamin $\mathrm{D}$ analogs, a practice driven by current financial incentives and in stark contrast to other countries, where most patients receive oral vitamin $\mathrm{D}$. Use of intravenous vitamin D will decline overall and if given intravenously, may switch to less expensive calcitriol. Oral supplementation will be adopted to a greater extent, again predominantly with generic calcitriol. Since the inclusion of oral-only ESRD drugs was postponed until 1.1.2014, current practice patterns of oral phosphate binders are unlikely to change, but one can anticipate a surge in calcimimetic use. Coverage of cinacalcet will remain with Medicare Part D for another 3 years, and it will likely be used as a substitute for vitamin D therapy in some patients, again following financial incentives.

\section{Other Medications in the Bundle}

With the inclusion of medications used to maintain or regain the patency of vascular access, it is likely that such problems will be more frequently addressed in the hospital setting in the future. The same pertains to the management of vascular access infections. Since the PPS does not include the costs for hospital care in the bundle, there is little incentive to address such problems in the outpatient setting, especially since patients experiencing access issues are also likely to require more aggressive anemia care.

\section{Conclusions}

The new PPS for ESRD care will have fundamental impact on the way medications will be used in the dialysis setting. Inadequate evidence on the comparative effectiveness and safety of competing treatment strategies facilitates justifying such swings in practice. While comparative effectiveness research is increasingly being conducted to study these treatment strategies, it will take several years until such evidence will be available. Much of 
that newly generated evidence will likely need to be tested in subsequent trials, and industry might not be interested in conducting such studies. To make sure that patients do not experience reduced quality of care, quality control programs will be implemented. Two of the currently proposed quality indicators focus on anemia care: proportion of patients with hemoglobin concentrations above 12 $\mathrm{g} / \mathrm{dl}$ and the proportion of patients below $10 \mathrm{~g} / \mathrm{dl}$. Clearly, more quality indicators are needed to safeguard patients, but the evidence supporting any other indicators, e.g. in the bone and mineral metabolism domain, is limited and subject to interpretation. It can be anticipated that the bottom line of (large) dialysis providers will be enhanced, at least in the short run, as they move towards increasing efficiency. The CMS will be able to curb the growth of their ESRD expenditures. Unfortunately, the effects of the overall program on patient outcomes are uncertain and will be difficult if not impossible to monitor.

\section{References}

1 United States Renal Data System, USRDS 2009 Annual Data Report: Atlas of EndStage Renal Disease and Chronic Kidney Disease in the United States, Chapter 11: Costs of ESRD. National Institutes of Health, National Institute of Diabetes and Digestive and Kidney Diseases, Bethesda, 2009, pp $335-342$.
-2 Powe NR, Griffiths RI, de Lissovoy G, Anderson GF, Watson AJ, Greer JW, Herbert RJ, Eggers PW, Milam RA, Whelton PK: Access to recombinant erythropoietin by Medicareentitled dialysis patients in the first year after FDA approval. JAMA 1992;268:1434-1440.

-3 Medicare Program; End-Stage Renal Disease Prospective Payment System. 42 CFR Parts 410, 413 and 414. Fed Regist 2010;75:4902949214.
4 Chertow GM, Winkelmayer WC: On the relative safety of intravenous iron formulations: new answers, new questions. Am J Hematol 2010;85:643-644. 